\title{
Fundamentals of metatheoretical understanding of nature based on comprehensive reflection of discourse
}

\author{
Sergey N. Bredikhin ${ }^{1, *}$, Tatiana V. Marchenko ${ }^{1}$, Nataliia A. Pelevina ${ }^{2}$, and Iuliia I. Pelevina ${ }^{2}$ \\ ${ }^{1}$ North Caucasus Federal University, Translation Studies Department, 1, Pushkin Str., 355017 Stavropol, Russia \\ ${ }^{2}$ Armavir State Pedagogic University, Department of Foreign Languages and Teaching Methodology, 159, R. Luxemburg St., 352901 , \\ Armavir, Russia
}

\begin{abstract}
The study provides rationale for meta-theoretical interpretation of a special type of a literary text - the one based on ultimate reflexion. The analysis rests on "camp prose" works characterized by a significant degree of abstraction on the part of the subject of narration and the possibility of contaminating the objective reality phenomena and the ones of personal reflexive reality within the framework of an "objective" observer description. The authors specify the meta-language of the first level abstraction and the peculiarities of constructing the analyzed type of text as a certain acting scheme for both the literary text producer and the recipient. The proposed scheme incorporates a peculiar cognitive experience (featuring creativity, abstraction, intuition and reflexivity) and a new phenomenological reflexion that imply a new way of realizing different types of experience within the scope of reflexive reality. The texts based on ultimate reflexion are defined as verbal-psycho-emotive entities that can trigger a certain state of consciousness in the process of reading and objectify different sense overtones implied by the author.
\end{abstract}

\section{Introduction}

The meta-theoretical approach to the discourse based on comprehensive reflexive self-analysis of psychoemotional sphere can be studied within the paradigm of objective reality and the being of this reality as the basic aspect of objectivized reflection, i.e. symbol and psyche / mentality objectification. In this case, ontology is a way to go beyond the objectification of these categories and look for their being or knowledge of them. The understanding is supposed to be in a sign form (as certain substitution objects for objective reality things). It follows from the above that the object of ontological studies of psycho-emotive aspects of being is not only a sign and the being itself (as the real being) but the real things in existence as well. The works of different literary artists feature this as a kind of a roundabout way of reaching reflexive existence through real life existence, as it often happens in the so-called "camp prose". It is significant to study the phenomenon represented in an abstract form. Most evidently, the corealization represents both the real and the being [1]. The topic of combining several approaches to the interpretative potential analysis of ultimate reflection discourse, as actualized in literary works of "camp prose", and the meta-theoretical foundations in speech production of the given type of texts, seems essential. It is preconditioned by the fact that the psychological and emotive sphere as such is not the prerogative of linguistics. However, its introduction into a purely linguistic (discourse) study appears to be of special relevance nowadays. Indeed, it is indisputable that the representation of inner psychic reality and personal experience in a vivid (emotional) and convincing way is only possible in verbalization space [2]. A symbol serves as some objectification of consciousness (in its work with a thing). As we have already mentioned, a symbol reveals a double-facet nature incorporating the world of things and the world of reflexive consciousness reality.

\section{Methodology}

Hermeneutic-noematic analysis appears to be the basic method in de-objectivation of reflexive reality that is objectivized in discourse. A symbol is intentionally introduced here due to its double-facet nature as it provides a material field for the experiment. There is also mental necessity to work precisely with consciousness and turn it into meta-consciousness. It is not a spontaneous phenomenon based on intuitive noematic reflexion only. However, consciousness objectivation, i.e. its introduction into interpretation, is only possible in case of the meta-theoretical approach of "understanding the consciousness work".

The spontaneous character of ordinary consciousness is not represented in object terms for description. Consequently, it is impossible in principle to study nonobjectivised ideas about mental constructs acting as elements of the psycho-emotional sphere. It is infeasible to work with mentality directly. However, it is possible to analyze its work or hermeneutic understanding of these constructs, as there is noematic reflection of the

\footnotetext{
* Corresponding author: bredichinsergey@yandex.ru
} 
first level that constructs mental phenomena and entails verbalization when we talk about facts of objective reality. At the third level of abstraction with the reference to phenomenological reflection and the metatheoretical approach, we come to the thought of overthinking. It means that the understanding and the noematic reflection of the real world facts serve as some interpretation language that is understood intuitively prior to the interpretation itself. The consideration of direct and indirect experiences in analysis is objectively necessary. However, the existence of certain markers demonstrating the mental acts of consciousness for direct experience can be considered as the existing ones only a priori. These markers are not located entirely in the sphere of the tangible world. Otherwise, the fact would precondition the study of comprehensive reflection discourse senses solely within linguistics and literary studies domain and would reduce it to the analysis of material verbalized constructions only. In the process of the hermeneutic-noematic analysis of empirical material represented in the works of "camp prose", it appears to be relevant to include the elements of conceptual selection, descriptive-analytical and contextological analyses in its integrative part. In this case, they make up the linguistic base for a complex methodology of interpreting the processes of objectifying and reobjectifying of components representing conceptualized units at different levels. Different methods of analysis within the frame-oriented theories of expressing [3] various shades of conceptually essential constructs are efficient for the extra-linguistic analysis of psychoemotive stereotypical situations that form the vertical context for the production of an ultimate reflection text. As M. Bakhtin noted, the study of a literary text is to be based on linguistics but not to be confined to it, for a sequence of tropes does not make a literary text [4].

\section{Findings and discussion}

Both for the producer and the recipient, mental constructs and consciousness processes appear to be something they are present at since they are the subjects experiencing the understanding. Thus, this phenomenon cannot be an object that is isolated from the subject. Namely, the author distances himself from the fact that he is immersed into objective reality of the "camp being", as well as from personal associates, thoughts and "introversive submergence", and describes the events as an outside "objective" observer. The given approach allows nominating such connections meta-connections, an object - a quasi-object, and the situational context - a meta-attitude.

Describing the states, opportunities and peculiarities of mental constructs verbalized in the psycho-emotive discourse of the "camp prose", we destruct the conditions for existence of the objects under consideration. For that very reason, their being is the being-to-death (Sein-zum-Tode) as so far they do not exist in the context in their application; we trepan dead consciousness. We can apply the terms "the subject" and "the object" only in the context of their functioning in meta-language, actualizing them in understanding / overthinking of mental constructs. The acting of both the producer's and the recipient's psycho-emotive mental constructs lies in Cartesian discourse strategies. Anything that "a submerged author" tries to think over, fixing as a part of a whole picture of the thinking subject himself, turns co-knowledge in all its facets into an irremovable part of any cognition. It comes as a crucial aspect in every sense structure of a psycho-emotive text based on the reflection over one's own existence and consciousness. An essential condition is the introduction of additional definitions of hierarchical superstructure of the sense, a new meta-language. Under the conditions of total mental character, it turns out that anything capable of being represented in language structures is marked by co-knowledge. For this reason, along with categorized notions it is necessary to take into consideration a multitude of examples, contexts and actualizations that are possible even hypothetically. It is at this stage when the specification itself becomes unreasonable. The specification, in its turn, is not about differences in certain categorizing features of mental constructs and the facts of the real world. The latter serve as a characteristic of some fact similar to objects of the reality. Under the conditions of renunciation from mentality, it possesses a completely different quality characteristic. The specification concerns the idea that they are some "impossible possibilities" existing both a priori and a posteriori. It means that their over-thinking and description will be expressed in the notions of metalanguage and meta-theory, though it is not a language or a theory different from the ones of natural description: they are a new non-usual interpretation of the natural language of subject description.

In this case, some meta-language turns out to be not just the language of description of different psychic phenomena that possess referential correlation only and do not reveal any denotative one. It serves a means of experimenting, both sense and knowledge production, understanding and cognition processes. In this aspect, the language is a phenomenon ranked in the same way as cogitative constructs, reflection over one's own experiences and the consciousness in general. It functions only along with existence of some metaobjects, general ideas about the objects of the real world (if one is to analyze the forms of knowledge in general) or about the objects of reflexive reality (if one dwells upon some phenomenon expressing the inner world). In the first case, it is the primary meta-language of the second level of abstraction. The utterances expressed in this language can convey noematic reflection and pragmatic correlations of "homo cogitans" with semiosis context in the form of pragmemes, and these are just the conditions of its work, not a hermeneutic vision of the language or its mental constructions. So far, it is not capable of conveying the attitude of the producer to the language or mental constructions. Its correlation with the language of the third level of abstraction (metalanguage) is not expressed through the object-subject opposition. Categorization and systematization of the language of the first level of abstraction form the system of myth creation: the objects of this meta-language turn 
into world and routine life images. In this world image, both the language and the mental constructs will be the quasi-objects of understanding.

The functioning of the language of the third level of abstraction endorses the idea that there is no external observer as regards the mental constructs. There cannot be a reproducible context of sensitive experience. In case we assume the latter, we inevitably reduce the study of hierarchical superstructures to an ordinary linguistic analysis, thus failing to take into account all the variety and the diversity of this material-ideal phenomenon.

For instance, A. Solzhenitsyn differentiates the languages from consciousness in each of his works. It is achieved by means of objectification of the inner world of his experiences, reference to sensualisms and identification of mentality and physicality. It is also relevant to differentiate verbalization means and mental hierarchical constructs that (both the former and the latter) serve the basis for sense production. Ignoring or prioritizing one of the aspects results in incomprehensive understanding. Following L. Wittgenstein, M.K. Mamardashvili assumes the intersection or concurrence of mental constructs with reflexive acts fixed by specific means in the language, where a referent is within the language and within the utterance. The examples of such constructions are as follows: "I think.../ I know.../ I believe...". The above-mentioned utterances convey something that provides a language characteristic to the cognitive act but it has nothing to do with the categorical characteristic of the language itself. It is a self-reference (a self-referring system) independent of language features. The use of the notion "symbol" is based on its double nature. It provides the material space for the experiment. There is a mental necessity to work precisely with consciousness turning it into metaconsciousness that is not a spontaneous phenomenon based on purely intuitive noematic reflection. "Consciousness can be treated both consciously and unconsciously. The unconscious approach views consciousness as an instance of reflection and comprehension, i.e. consciousness itself performs as a special cognitive process. In this case, consciousness stays "where it belongs", nothing "happens to it" [5]. However, consciousness objectification and its analysis are only possible in case there is a meta-theoretical approach that entails the "reflection over the work of consciousness". It is carried out to study something that is different from consciousness and is not the objective reality to full extent that is life as it is. In Symbol and Mind M.K. Mamardashvili and A.M. Pyatigorskiy carry out the interpretative analysis of Freud's works devoted to subconsciousness as pre-consciousness, unconscious consciousnesses, its outer reflective part. According to the scholars, S. Freud's psychoanalysis is not the only way to turn consciousness into meta-consciousness and provide it with modus. Minimal marking is acquired by reflexive acts of thought-acting in the language that expresses the inner world of homo reflectibus. As M.K. Mamardashvili and A.M. Pyatigorskiy claim, "some structures of language thinking are more connected with the absence of consciousness rather than with its presence... It is impossible to understand consciousness by means of the text study. At best, consciousness becomes "perceptible". A text can be created without consciousness, it can be produced. Whereas consciousness cannot be produced by any linguistic device primarily because consciousness turns up in the text not due to some language regularities, that is from within the text, but due to some regularity of the consciousness itself" [5]. Linguistic expression of the reflected psycho-emotive act cannot be characterized by the act of reflection itself. Text blocks provide only the hierarchical structure of complex syntactic and stylistic constructions.

The existence of language oppositions represents neither mental activity processes nor the mental activity itself. However, one can identify the presence of mental operations in the transition from one opposition to another. Namely, meta-connections of transition to different language conditions, the mere fact and dynamics of transition is an indirect indication of mental processes that require objectification in a psychological text. It should be noted that the clarification of mental processes from the point of view of linguistic oppositions is impossible, straight conversely the former allow interpreting the fact of opposition existence. The dynamic condition of structure change can be defined as thought-acting. In general, the area of mental structures and the system of linguistic oppositions is the space of mechanical work of consciousness in the processes of differentiating objective and reflexive world, as well as opportunities of representing the latter by means of the notions typical of the former. Such transitions and paraphrases are possible only under the condition of specific organization, harmony and the semantic capacity of the constructed discourse act [6]. When the subject of thinking changes the usual structure of linguistic thinking, his presence in a certain usual state of thinking indicates the intentional escape from the structure of the realized.

The text based on ultimate reflexivity is not the case of obvious presence of thought-acting instances in itself. The mental acts are conveyed in it through the system of self-referring elements (the physical matter is actualized in the notions of the psychological one and vice versa). In terms of objectification of the general text sense one can say that "with reflection awakening the experience revives and realizes the horizon (that is sense enlargement takes place), what is more it happens in a way other than it can be during original experience" [7]. The form is represented in the language system as a phenomenon induced by the context of speech and thinking, the emotive situation of renunciation on the part of the author-interpreter from his own position. The mere fact, that this phenomenon is observed, can be viewed as a meta-theoretical production.

The common feature of the very part of cognition that employs meta-theory for understanding / cognition can explain the above-mentioned statements. This common feature is incomprehensible in existential discourse. It is analysed with the reference to the "abstraction" technique as it enables the escape from formal-logical things and reveals the "stream of consciousness" area. The feature can be viewed as the 
identity of the phenomenon itself and its interpretation. They can be represented as "the sum of the given on the beam of reflection with inward direction, and is supposed to constitute a certain pole of personal senses (hierarchically structured constructs composed of relevant facets of a noem set)" [8]. There is a wide range of examples in psychological texts of "camp prose" featuring the difference in objective reality and its comprehension. Notably, in many cases it does not convey any directly perceived sense. Even under conditions when it makes sense, the mechanisms that produce it are similar to such an extent that their differentiation is inconsistent as the author's perception can change as regards reflexive reality. Not only comprehension and memory can be presented as a mental process generating some "self-referring image", a system of relations of the mere possibility of linguistic expression (the language) and the produced psychological text (the speech). The dominants at interpretation and comprehension stages of these processes are as follows: 1) the temporary framework of text production and perception, 2) the constant of recipient's background knowledge, 3) individual peculiarities and cognitive-valency system of the reader, 4) recipient's aims, 5) ideological and aesthetic views of the reader and their resonance (or its absence) with ideological and aesthetic potential of the text [9]. One may claim that there is perception in any process objectified as a cognitive act, and in any process incorporating perception there is a mental act of cognition. It means that cognition is actualized by the author as regards his / her personality and the influence of the external world, the comprehension of these processes and their principles.

The sphere of meta-theoretical analysis of the reflection discourse can provide the way to avoid the contradictions of classics - taking us away from the precipice of objectifying the mental acts. The classical reality of mental acts of co-realization fails as they are supposed to be represented in a different way in verbalization or in other predetermined forms.

The state of psycho-emotive mental act is not a substantive category. It can be applied to a particular objective content only. There is no univalent interpretation in correlation of content aspects and conditions as there are no verification procedures for correlations of this kind. Any recipient of such a text develops his own series of associations in line with his / her empirical and reflexive experience - the life itself teaches him to comprehend and to feel. In fact, this ambiguity and multifaceted character reveal metatheoretical nature. Here arises another meta-theoretical notion - the text produced by mental acts. The text viewed with the account of these assumptions is something read by consciousness, its reading is a kind of state of consciousness. Nevertheless, a state is defined as specifying something empty. The reader assumes some special facet that is invisible in noematic reflection. The state is reading such a text that arises in the mental act of the reading itself. The recipient plunges into the state of the author himself / herself, experiences and empathizes. The state is the fact the text is produced by reading, namely the text is read / realized by the text. Understanding is the production of a text, the recipient following the way the producer has gone. This quasitautology proves insufficient interpretation of such acts from the point of view of usual, common understanding, without integrative experience [10], something else is necessary. The development of this tautology is actualized in meta-theoretical interpretation of how mental acts work.

Every discourse act based on reflection not only over ontological but over the given ontological is a special non-usual text arising in the process of reading. Generally it appears to be the state of consciousness, "the final, flashing connection, locking of the one who realizes with what he / she realizes; or some situation of the "realizing" realized and something that arises in the act of realizing this something is the state of consciousness" [5].

\section{Conclusion}

Thus, the conditions of reflecting mental acts offer an opportunity to interpret their realization as it is. At the same time, the psycho-emotive discourse of "camp prose" does not stand out from potential / hypothetical texts, reading which would induce some state of consciousness as the definition itself does not possess any immanent characteristics to interpret them as something different. Such characteristics will arise only in meta-theory that takes into account and refers to a particular cultural tradition, for instance, the Russian tradition of empathizing and excusing the convicted ones. When the acts of realizing and empathizing are empowered by such subjective characteristics, "consciousness realizes itself in the forms of physical representation". It results in the immersion into objectification of mental acts. Notably, it can be achieved not only by constant reflexive references to meta-theoretical position but by means of special forms of narration that are actualized in the "camp prose" under consideration. Realization and renunciation in this type of discourse is based on the attachment to the real world, as transcendental reflection is not a reflective act of a transcendental subject that develops in the process of correlation with empiricism. The reflective act is missing in this case. The structure and the linguistic expression of the psycho-emotional discourse based on ultimate reflexion is the content that is abstract from the state. It is a space characteristic, a range of certain consciousness phenomena viewed as consciousness texts.

\section{References}

1. M. Štúr, XLinguae, 6-4, 2-17 (2013)

2. A. Pokrivcak, S. Pokrivcakova, A. Buda, XLinguae 9-1, 127-134 (2016)

3. D. Ritchie, Metaphor and Symbol 20-4, 275-294 (2005) 
4. M.M. Bakhtin, Written word aesthetics (Iskusstvo, Moscow, 1979)

5. M.K. Mamardashvili, A.M. Pyatigorskiy, Symbol and Mind. Metaphysical Reasoning on Mind, Symbolics and Language (Yaziky russkoi kultury, Moscow, 1997)

6. N.V. Cheremisina, Analysis of a Literary Text 2, 32-43 (1976)
7. G.I. Bogin, The Substantial Aspect of Text Comprehension (TGU, Tver, 1993)

8. S.N. Bredikhin, Humanitarian and Social Sciences, 2, 117-129 (2013)

9. Yu.M. Lotman, Articles on Semiotics of Culture and Art (Akademicheskiy Proyekt, Sankt Peterburg, 2002)

10. S.N. Bredikhin, R.S. Alikaev, Issues of Cognitive Linguistics, 2 (47), 123-128 (2016) 